\title{
Investigation of barriers to clinical practice guideline-recommended pharmacotherapy in the treatment of COPD
}

\author{
Lea PRICE, Sarah J. BILLUPS, Melissa A. RICE, Cynthia HARTSFIELD.
}

\begin{abstract}
${ }^{*}$
Background: The adoption of clinical practice guideline recommendations for COPD is suboptimal. Determining the barriers to the implementation of these practice guidelines may help improve patient care.

Objective: To determine whether barriers to the use of pharmacotherapy according to practice guidelines are related primarily to patient or prescriber factors.

Methods: Retrospective cohort study. Members of a health maintenance organization identified as having spirometry-defined COPD ranging from stage II to IV. Electronic medical records were reviewed for documentation of the following: 1) patient affordability issues, 2) history of an adverse drug reaction, 3) history of inefficacy to therapy, and 4) prescription history.

Results: A total of 111 medical records were reviewed. There were $51 \%$ of patients who had not filled medications that had been prescribed in accordance with guidelines and $43 \%$ did not have the guideline recommended medications prescribed in the previous year. Only $4 \%$ and $2 \%$ of patients had documented inefficacy and affordability issues, respectively. There were no reported cases of adverse drug reactions.

Conclusions: This study provides insight to the acceptance of COPD treatment recommendations by patients and providers. Further research is needed to design interventions to reduce barriers and optimize COPD treatment.
\end{abstract}

Keywords: Pulmonary Disease, Chronic Obstructive. Practice Guidelines. Drug Therapy. Patient Compliance. United States.

Lea PRICE. PharmD. Clinical Pharmacy Primary Care Specialty Resident, Kaiser Permanente Colorado, Denver, CO (USA).

Sarah J. BILLUPS. PharmD. Clinical Pharmacy Specialist at Kaiser Permanente Colorado, Denver, CO. Clinical Assistant Professor, School of Pharmacy, University of Colorado at Denver and Health Sciences Center, Denver, CO (USA).

Melissa A. RICE. PharmD. Clinical Pharmacy Specialist at Kaiser Permanente Colorado, Denver, CO. Clinical Assistant Professor, School of Pharmacy, University of Colorado at Denver and Health Sciences Center, Denver, CO (USA).

Cynthia HARTSFIELD, PhD. Clinical Research Unit, Kaiser Permanente Colorado, Denver, CO. Clinical Assistant Professor, School of Pharmacy, University of Colorado at Denver and Health Sciences Center, Denver, CO (USA).

\begin{abstract}
RESUMEN
Antecedentes: La adopción de recomendaciones de las guías de práctica clínica es sub-optima. Determinar las barreras para la implantación de estas guías de práctica puede ayudara mejorar la atención al paciente.

Objetivo: Determinar si las barreras para el uso de la farmacoterapia de acuerdo con las guías de práctica están fundamentalmente relacionadas con variables del paciente o del prescriptor.

Métodos: Estudio de cohorte retrospectivo.

Miembros de una organización de gestión de la salud identificados por tener EPOC definida por espirometría entre los estadios II a IV. Se revisaron los historiales médicos electrónicos para documentar lo siguiente: 1) capacidad económica del paciente, 2) historial de reacciones adversas, 3 ) historial de ineficacia del tratamiento, y 4) historial de prescripción.

Resultados: Se revisó un total de 111 historiales médicos. Hubo un $51 \%$ de pacientes que no había completado la medicación que le habías ido prescrita de acuerdo con las guías y un $43 \%$ no había recibido las prescripciones recomendadas en las guías en el último año. Sólo un $4 \%$ y un $2 \%$ de pacientes había documentado problemas de ineficacia y de capacidad económica, respectivamente. No había registrados casos de reacciones adversas medicamentosas. Conclusiones: Este estudio proporciona una visión de la aceptación del as recomendaciones del tratamiento de EPOC por los pacientes y los proveedores. Se necesita un investigación para diseñar intervenciones que reduzcan las barreras y optimicen el tratamiento del a EPOC.
\end{abstract}

Palabras clave: Enfermedad pulmonaria obstructiva crónica. Guías clínicas. Farmacoterapia. Cumplimiento del paciente. Estados Unidos.

\section{(English)}

\section{INTRODUCTION}

Chronic obstructive pulmonary disease (COPD) is the fourth leading cause of morbidity in the United States and the death rate is continuing to rise. ${ }^{1}$ The financial burden associated with COPD is significant. In 2002, the total estimated cost of COPD in the United States was US\$32.1 billion, including healthcare expenditures of US $\$ 18$ billion and indirect costs of US $\$ 14.1$ billion. ${ }^{2}$ 
Clinical practice guidelines for the pharmacologic management of COPD have been available for over 10 years, with the most widely recognized being the Global Initiative for Obstructive Lung Disease (GOLD) Guidelines. ${ }^{1,3,4}$ These guidelines recommend use of a short-acting bronchodilator "as needed" plus scheduled bronchodilators (either a beta-agonist or an anticholinergic agent) in Stage II, III and IV COPD patients. Scheduled use of inhaled corticosteroids is reserved for Stage III and IV COPD patients who remain symptomatic and have frequent exacerbations despite scheduled bronchodilator treatment. ${ }^{3-5}$

Given existing medications do not modify the progressive decline in lung function associated with COPD, the goal of pharmacotherapy is to ameliorate symptoms and/or decrease exacerbations. For example, scheduled use of bronchodilators improves lung function, decreases use of supplemental albuterol, and lengthens the time to an acute exacerbation. ${ }^{6,7}$

Despite these results, clinical practice guidelinesrecommended pharmacotherapy for COPD is underutilized. ${ }^{8}$ A study of hospitalized COPD patients found that clinical practice guideline-based care was provided in only $66 \%$ of patients. ${ }^{9}$ If the scope of care were limited to pharmacotherapy alone, this figure rose to about $80 \%$. ${ }^{9}$ Another study of inpatient therapy for COPD found that at least 3 of 5 "Level A" clinical practice guidelines recommendations were followed in less than $60 \%$ of cases. $^{10}$ In an ambulatory population in Japan, pharmacotherapy appeared to be significantly underutilized as $31 \%$ of patients with moderatesevere disease received no medications at all. ${ }^{11}$

Although patient adherence to prescribed COPD pharmacotherapy has been investigated, ${ }^{12}$ it is unclear what barriers in the ambulatory setting contribute to the low utilization of clinical practice guideline-recommended pharmacotherapy. Barriers such as patient-related factors (financial or educational issues, health belief factors, health experiences, or health behaviors), ${ }^{13}$ or prescriberrelated factors (poor access to clinical practice guidelines, disagreement with or under-awareness of clinical practice guidelines) have been explored. ${ }^{14}$ Understanding the underlying reason(s) contributing to suboptimal acceptance of clinical practice guideline-based medication regimens will help in designing interventions to improve care. The primary goal of this study was to determine the extent to which barriers to implementation of clinical practice guideline-recommended pharmacotherapy were related to patient or prescriber factors.

\section{METHODS}

This was a retrospective cohort study conducted at Kaiser Permanente Colorado (KPCO). The study was approved by the Institutional Review Board of KPCO. KPCO is a group model, non-profit health maintenance organization that provides health care services to over 450,000 members in the DenverBoulder metropolitan area.
Prior to this study, we had previously identified patients with spirometry-defined COPD (Figure 1). ${ }^{15}$ Patients who had continuous KPCO membership with pharmacy benefits between July 1, 2001 and June 30,2003 , disregarding membership gaps of less than 60 days, were eligible for inclusion. We identified 5,184 patients with 2 diagnoses of COPD based on the International Classification of Diseases, 9th Revision, (ICD-9) coding system (491.xx, 492.xx, 496.xx) separated by at least 30 days. A random sample of 1000 electronic medical records was selected to abstract spirometry data. COPD was defined as a 1-second forced-expiratory volume (FEV1) / forced vital capacity (FVC) ratio of less than $70 \%$. Patients were classified per GOLD criteria as stage II, stage III, or stage IV.

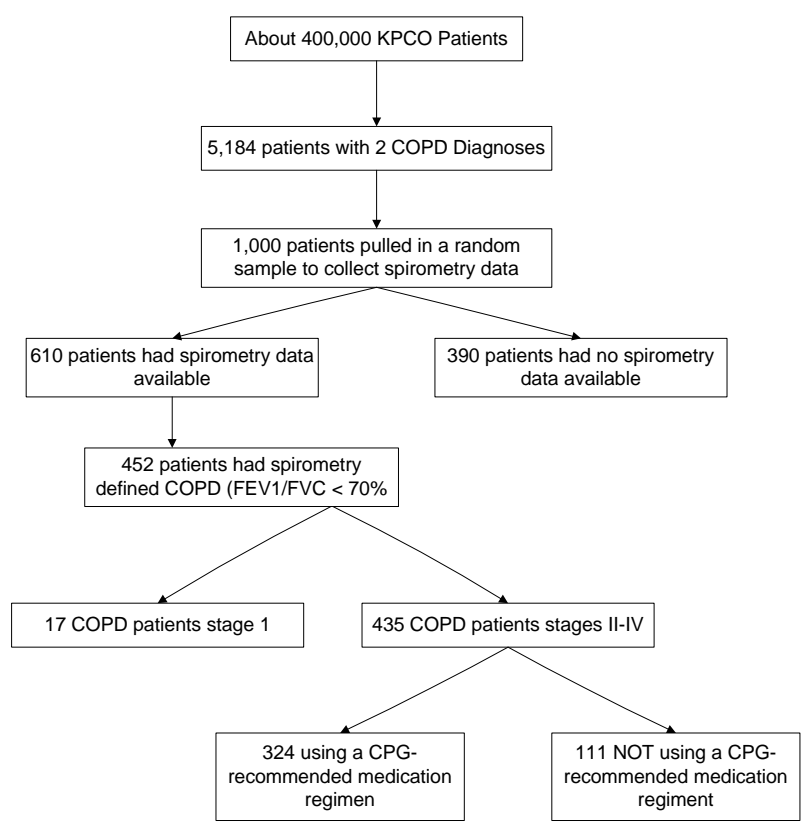

Figure 1: Patient population with spirometry-defined COPD

Electronic pharmacy databases were used to identify patients underutilizing clinical practice guideline-recommended COPD medications during the 6 months following the initial COPD diagnosis of the study period (which was defined as the index date). Underutilization was defined as any one of the following: a) using no medication for COPD, b) using only an unscheduled short-acting bronchodilator, or c) using an inhaled corticosteroid in the absence of a scheduled bronchodilator. A scheduled bronchodilator was defined as use of: i) a long-acting beta-agonist, ii) ipratropium bromide, or iii) a short-acting beta-agonist with sufficient quantity filled during the 6-month study period to equate to at least 6 puffs per day.

For patients identified as not using a clinical practice guideline-recommended medication regimen during the study period, electronic medical records were reviewed to identify the following pre-defined patient-related factors: 1) affordability issues (evidenced by documentation of such in a progress note or patient referral to an internal or external cost-assistance program), 2) documentation of an adverse reaction to the recommended medication, 
and/or 3) documented history of inefficacy with the recommended medication. If none of these factors were recorded in the electronic medical record, the patient's prescription history was reviewed for the 12-month period prior to the index date to determine if the clinical practice guideline-recommended therapy had ever been prescribed. Patients were categorized into one of two groups: 4) medications had been prescribed per COPD clinical practice guidelines but never filled (patient-related factor), or 5) medications had not been prescribed in the previous year (prescriber-related factor).

For all patients with spirometry-confirmed COPD, electronic databases were used to identify those with an ICD-9 coded diagnosis for asthma (493.xx) during 1 year before and 6 months after the index date.

The study analysis was primarily descriptive. Baseline characteristics between the patients categorized as using or not using a clinical practice guideline-recommended medication regimen were compared using chi-square for dichotomous variables and Student's t-test for continuous variables. Two-tailed $P$-values less than 0.05 were considered statistically significant.

\section{RESULTS}

Of the 1,000 electronic medical records randomly selected for abstraction to identify patients with spirometry-confirmed COPD (see Figure), 452 patients were identified, for which 435 met GOLD criteria for stage II, III or IV. Of these 435 patients, $111(26 \%)$ were not receiving a clinical practice guideline-recommended medication regimen and underwent further electronic medical record review (Table 1). There were no statistically significant differences between the patients who were and were not receiving clinical practice guidelinerecommended pharmacotherapy in terms of sex, age, or a diagnosis of asthma. The group receiving clinical practice guideline-recommended pharmacotherapy had more severe disease. The majority of patients had their COPD managed by internal medicine physicians $(84 \%)$, and the remainder by family practice physicians. One out of five patients had at least one visit with a pulmonologist during the study period.

\begin{tabular}{|l|c|c|c|}
\hline \multicolumn{1}{|c|}{ Table 1: Patient Characteristics } & $\begin{array}{c}\text { NOT } \\
\text { Receiving CPG- } \\
\text { Recommended } \\
\text { Pharmacotherapy } \\
\mathrm{n}=111\end{array}$ & $\begin{array}{c}\text { Receiving CPG- } \\
\text { Recommended } \\
\text { Pharmacotherapy } \\
\mathrm{n}=324\end{array}$ & P-value \\
\hline Male (\%) & $\mathbf{5 4 ( 4 8 \% )}$ & $182(56 \%)$ & 0.21 \\
\hline Mean Age in years (+/- SD) & $\mathbf{7 0 . 9 + / - 9 . 2}$ & $69.5+/-8.6$ & 0.14 \\
\hline COPD Severity & & & $<0.001$ \\
\hline Moderate & $52(47 \%)$ & $89(27 \%)$ & \\
\hline Severe & $47(42 \%)$ & $138(43 \%)$ & \\
\hline Very Severe & $12(11 \%)$ & $97(30 \%)$ & 0.05 \\
\hline Asthma diagnosis & $12(11 \%)$ & $63(19 \%)$ & \\
\hline CPG = Clinical practice guidelines & & \\
\hline
\end{tabular}

There were few documented reasons noted in the electronic medical records for the 111 patients who did not fill medications consistent with clinical practice guidelines. Four patients (4\%) had documented inefficacy with the recommended medication and 2 patients (2\%) had affordability issues. There were no reported cases of adverse reactions to the prescribed medication. For the remaining 105 patients, 57 (51\%) had medications prescribed according to COPD clinical practice guidelines that were never filled. For the remaining $48(43 \%)$, the recommended medications had not been prescribed in the previous year.

\section{DISCUSSION}

Our study investigated possible barriers to clinical practice guidelines adherence for the pharmacologic treatment of COPD in an outpatient setting and categorized these into patient- and prescriber- related factors. About $26 \%$ of patients with spirometry-defined stage II or worse COPD were not using a clinical practice guidelinerecommended medication regimen. The use of clinical practice guideline-recommended medications in our study population was higher than that reported in another ambulatory care population. ${ }^{11}$ The reasons for this difference are unclear, but our care model may be a factor. Coordinated managed care systems, such as ours, have been shown to increase adherence to clinical practice guidelines in other disease states. ${ }^{16,17}$ For the majority of patients categorized as not using clinical practice guideline-recommended pharmacotherapy, the medications had been prescribed but were simply not filled. The reasons patients neglected to fill the prescribed medications were not ascertained. Affordability issues, adverse medication reactions, and history of inefficacy with recommended medications may have been more common than detected in our study as they may not have been documented in the electronic medical record. To more accurately define specific reasons for not filling prescribed clinical practice guidelinerecommended medications, we are currently conducting a patient-directed survey.

There were several potential limitations to our study. Data collection pertaining to reasons for nonadherence to clinical practice guidelines relied on electronic medical record reviews, which are subject to the same limitations of any retrospective medical record review. Secondly, our broad definition of 
"patient-related" and "provider-related" factors lacks the precision of other methodologies such as surveys. Although this study was limited to patients with spirometry-defined COPD, it is possible that this population does not represent patients without this diagnostic test, limiting the generalizability of our results. However, the fact that all our study patients had medically confirmed COPD increases the internal validity of our study. Lastly, GOLD guidelines were not published until 2001 which was the beginning of our study time period. Therefore, some physicians may not have fully adopted them into practice, despite the release of other similar international guidelines six years earlier. ${ }^{3,4}$

Our study investigated the possible barriers to adherence of clinical practice guidelines through electronic medical record review in an outpatient setting. We believe our results provide valuable insight on possible barriers that impact clinical practice guideline-recommended treatment of COPD. We plan to further investigate barriers to clinical practice guidelines through patient and physician surveys. The results of these surveys may elucidate underlying barriers to clinical practice guideline-based treatment and enable us to design a targeted intervention and/or educational program to reduce barriers and optimize COPD treatment.

\section{ACKNOWLEDGEMENTS}

Portions of this research were presented at the ATS 101st International Conference, San Diego California, USA May 20-25, 2005.

This research was supported in part by a grant from the Pfizer Global Pharmaceuticals U.S. Outcomes Research Group.

\section{References}

1. National Heart, Lung, and Blood Institute/World Health Organization. Global Initiative for Chronic Obstructive Lung Disease. Global Strategy for the Diagnosis, Management, and Prevention of Chronic Obstructive Pulmonary Disease. NHLBI/WHO Workshop Report- Executive Summary. 2005. Available at: www.goldcopd.com. (Accessed December 12 2006).

2. National Institutes of Health: National Heart, Lung, and Blood Institute. Chronic obstructive pulmonary disease. NIH Publication 03-5229, 2003 March. Available at: http://www.nhlbi.nih.gov/health/public/lung/other/copd_fact.pdf. (Accessed August 15, 2006).

3. American Thoracic Society. Standards for the diagnosis and care of patients with chronic obstructive pulmonary disease. Am J Respir Crit Care Med. 1995;152:S77-S121.

4. Siafakas NM, Vermeire P, Pride NB, Paoletti P, Gibson J, Howard P, Yernault JC, Decramer M, Higenbottam T, Postma DS, et al. Optimal assessment and management of chronic obstructive pulmonary disease (COPD). The European Respiratory Society Task Force. Eur Respir J. 1995;8:1398-1420.

5. National Heart, Lung, and Blood Institute/World Health Organization. Global Initiative for Chronic Obstructive Lung Disease. Global Strategy for the Diagnosis, Management, and Prevention of Chronic Obstructive Pulmonary Disease. NHLBI/WHO Workshop Report- Executive Summary. 2001. Available from: www.goldcopd.com. (Accessed December 12, 2006)

6. Mahler DA, Donohue JF, Barbee RA, Goldman MD, Gross NJ, Wisniewski ME, Yancey SW, Zakes BA, Rickard KA, Anderson WH. Efficacy of salmeterol xinafoate in the treatment of COPD. Chest 1999;115:957-65.

7. Ulrik C. Efficacy of inhaled salmeterol in the management of smokers with chronic obstructive pulmonary disease: a single centre randomized, double blind, placebo controlled, crossover study. Thorax. 1995;50:750-4.

8. Matheson MC, Abeysena C, Raven JM, Skoric B, Johns DP, Abramson MJ, Walters EH. How have we been managing chronic obstructive pulmonary disease in Australia? Int Med J 2006;36(2):92-9.

9. Lindenauer PK, Pekow P, Gao S, Crawford AS, Guierrez B, Bejamin EM. Quality of care for patients hospitalized for acute exacerbations of chronic obstructive pulmonary disease. Ann Intern Med 2006;144:894-903.

10. Harvey PA, Murphy MC, Dornom E, Berlowitz DJ, Lim WK, Jackson B. Implementing evidence-based guidelines: inpatient management of chronic obstructive pulmonary disease. Intern Med J 2005;35:151-5.

11. Takahashi T, Ichinose M, Inoue H, Shirato K, Hattori T, Takishima T. Underdiagnosis and undertreatment of COPD in primary care settings. Respirology 2003;8:504-8.

12. Rand CS, Nides M, Cowles MK, Wise RA, Connett J. Lung Health Study. Long-term metered-dose inhaler adherence in a clinical trial. Am J Respir Crit Care Med 1995;152:580-8.

13. George J, Kong DC, Thoman R, Stewart K. Factors associated with medication nonadherence in patients with COPD. Chest 2005;128:3198-3204.

14. Brand C, Landgren F, Hutchinson A, Jones C, MacGregor L, Campbell D. Clinical practice guidelines: barriers to durability after effective early implementation. Intern Med J. 2005;35:162-9.

15. Hartsfield CL, Shetterly S, Palen TE, McCoy M, Marton JP. COPD: Treatment and utilization patterns in managed care. Am J Respir Crit Care Med 2005 [Abstract \#A541].

16. Sandhoff BG, Nies LK, Olson KL, Nash JD, Rasmussen JR, Merenich JA. Clinical pharmacy cardiac risk service for managing patients with coronary artery disease in health maintenance organization. Am J Health Syst Pharm 2007;64:77-84.

17. Witt DM, Sadler MA, Shanahan RL, Mazzoli G, Tillman DJ. Effect of a centralized clinical pharmacy anticoagulation service on the outcomes of anticoagulation therapy. Chest 2005;127:1515-22. 